Check for updates

The BMJ

Cite this as: BMJ 2021;372:n201 http://dx.doi.org/10.1136/bmj.n201 Published: 21 January 2021

\title{
Covid-19: Infections remain high in England with no evidence of decline since lockdown
}

\section{Elisabeth Mahase}

Prevalence of SARS-CoV-2 in the community has remained very high in the first 10 days of the third national lockdown in England, with no evidence of decline, results from the React-1 study have shown. ${ }^{1}$

The latest round of community testing included swab tests from 143 ooo people between 6 and 15 January 2021. Researchers from Imperial College London and Ipsos MORI found infections increased by 50\% from early December with 1 in 63 people infected. This is the highest figure the study has reported since it began in May 2020.

They warned that prevalence needs to be "reduced substantially" to ease pressure on the NHS and cut the number of deaths. Daily deaths are currently at a record high in the UK, with 1820 deaths within 28 days of a positive covid-19 test reported on 20 January. ${ }^{2}$

Paul Elliott, director of the programme at Imperial College London, said, "Our data are showing worrying suggestions of a recent uptick in infections which we will continue to monitor closely. To prevent our already stretched health system from becoming overwhelmed, infections must be brought down; if prevalence continues at the high rate we are seeing then hospitals will continue to be put under immense pressure, and more and more lives will be lost.”

In the latest round of testing, 1962 positives from 142 909 swabs were reported. This equated to a weighted prevalence of $1.58 \%$ (95\% confidence interval, 1.49\% to $1.68 \%$ )-the highest prevalence recorded by React-1 since it started in May 2020 and a more than 50\% increase from the last round of testing $(0.91 \%, 25$ November to 3 December).

Prevalence increased in all adult age groups, more than doubling to $0.94 \%$ in those aged 65 and over. Meanwhile, large household size, living in a deprived neighbourhood, and black and Asian ethnicities were all associated with increased prevalence.

Both healthcare and care home workers, and other key workers, also had increased odds of swab positivity compared with other workers. This comes as BMA council chair Chaand Nagpaul said the government can no longer ignore the calls for a review of personal protective equipment in light of "rocketing infection rates and a highly transmissible variant of the virus."

Looking at regional prevalence, the study found that the highest rates were in London $(2.80 \%)$, where it had more than doubled from $1.21 \%$ in the last round. Prevalence had also more than doubled in the south-east ( $0.75 \%$ to $1.68 \%$ ), the east of England (0.59\% to $1.74 \%$ ), and west Midlands (0.71\% to $1.76 \%)$.
Prevalence increased in the south-west (0.53\% to $0.94 \%$ ) and there was an apparent increase in the north west. For the other regions, there was an apparent decrease in prevalence in Yorkshire and the Humber while prevalence was broadly similar between the rounds in the east Midlands and north east.

Study author Steven Riley, professor of infectious disease dynamics at Imperial College London, said, "We are working to better understand why we are seeing these trends when the country is in lockdown, including studying the new variant, so that policy makers can respond urgently to help bring infections down and save lives.”

The researchers said that since there was a gap of over one month between this round and the last, the team said they may have missed a peak in prevalence. Other limitations included that the trends were based on data for a small number of days and could be biased by short term changes in testing behaviour among symptomatic people.

React- 1 round 8 interim report: SARS-CoV-2 prevalence during the initial stages of the third national lockdown in England. January 2021. https://spiral.imperial.ac.uk/bitstream/10044/1/85583/2/REACT1_r8a_final.pdf

2 Deaths within 28 days of positive test by date of death. https://coronavirus.data.gov.uk/details/deaths 